\title{
Development of Micropropagation Protocol in Simmondsia chinensis (Link) Schneider
}

\section{Veena Reddy, Srikanth Reddy M${ }^{1}$, S. Manoj Kumar ${ }^{2}$, B. Naresh ${ }^{1}$, B. Kiran Kumar1, B. Rama Devi and Prathibha Devi Cherku' ${ }^{*}$}

Arts and Science College for Women, Andhra Mahila Sabha, OU campus, Hyderabad, 500007, India

Key words: Micropropagation protocol, Simmondsia chinensis

Although initial experiments proved that BA could be used for shoot regeneration several other growth regulator combinations were used in the study with nodal explants (in case of both seedling and plantation trees). Five different culture media were used based on the MS or MMS duly supplemented by IAA, BA, Kn and AS. Highest regeneration response was recorded on medium-E (95 \pm 1 and $78 \pm 4$ ), which surpassed the medium-C (86 \pm 6 and $76 \pm 2)$, which contained AS. The use of only $4.0 \mathrm{mg} / \mathrm{l} \mathrm{BA}$ however resulted in a medium response. The combination of medium-E, based on MMS with IAA, BA and Kn was formulated in order to replace the use of adenine sulphate in medium-C which was expensive and also needed to be used in large quantities. Therefore the MMS with IAA $(1.0 \mathrm{mg} / \mathrm{l}), \mathrm{BA}(2.0 \mathrm{mg} / \mathrm{l})$ and $\mathrm{Kn}(2.0 \mathrm{mg} / \mathrm{l})$ could elicit a higher if not a better response in both seedling and plantation trees explants. Suitable rooting medium was also standardized with the supplementation of IBA $(3.0 \mathrm{mg} / \mathrm{l})$ to MS and by using lesser agar $(0.6 \%)$. After careful acclimation, a total of 201 plantlets could be successfully regenerated in a total period of 8 months from the date of inoculation of explants.

Jojoba is an evergreen perennial shrub, native of the Sonoran desert of Arizona and its neighboring regions. It is an evergreen, long-living, nonpoisonous, drought resistant, low maintenance and low-fire hazard plant with a deep root system. Jojoba was successfully cultivated as a commercial crop for a

*Author for correspondence: < prathi56@yahoo.com>. ${ }^{1 B i o t e c h n o l o g y ~ a n d ~ M o l e c u l a r ~}$ Genetics laboratory, Department of Botany, Osmania University, Hyderabad-500007, India. ${ }^{2}$ Institute of Biological Chemistry, Academia Sinica, 128, S-2, Academia Rd Taipei 11529, Taiwan. 
few years in several places of the world and later, problems were encountered and conservation strategies were looked into. Oil can be expelled from seeds either by an oil expeller or by solvent extraction. The oil is pure, clear, light yellow in colour, non-toxic and resistant to rancidity. Jojoba oil contains a long chain of alcohols and acids with double bonds, which differs slightly in the configuration from other natural fatty acids. The oil is a unique liquid wax ester comprising mainly $\mathrm{C}_{40: 2}$ and $\mathrm{C}_{42: 2}$ and is regarded as a replacement for sperm whale oil. Jojoba oil resembles the sperm whale oil and is used as a substitute by industries including pharmaceutical, plastic industries, petroleum, cosmetics and perfumes. It is stable, highly lipophilic, nontoxic, differs from common vegetable oils and animal fats as it is composed of $(67 \%)$ linear wax esters. Jojoba oil is a natural mimic of the oil secreted by human skin so it may be used to protect and lubricate skin to keep it supple and for haircare. The wax is also used as an industrial lubricant. Further, the seed-oil is used in several other applications especially to replace depleting fossil fuel reserves.

The present report deals with the development of micropropagation protocol for jojoba comprising the standardization of culture media for shoot regeneration from nodal explants, rooting, acclimatization and successful transfer of the regenerated plantlets to the field.

The seeds of jojoba (Simmondsia chinensis (Link) Schneider) were obtained from Central Arid Zone Research Institute, Jodhpur, Rajasthan, India and Association of the Rajasthan Jojoba Plantation and Research Project (AJORP), Jaipur,Rajasthan, India. Male and female plants were also procured from the above place and planted in the Botanical Garden of Department of Botany, Osmania University, Hyderabad, India.

Five different culture media were used based on the MS or MMS (Chaturvedi and Sharma 1989), duly supplemented by IAA, BA, Kn and adenine sulphate (ADS). Nodal explants were aseptically inoculated on each culture medium in $25 \times 150 \mathrm{~mm}$ culture tubes (which were autoclaved at $15 \mathrm{lbs} / \mathrm{pi}$ at $121^{\circ} \mathrm{C}$ for $20 \mathrm{~min}$ ). Three replicates were used for the study.

Highest regeneration response was recorded on medium-E (95 \pm 1 and $78 \pm$ 4), which surpassed the medium-C (86 \pm 6 and $76 \pm 2)$, which contained ADS. The use of only $4.0 \mathrm{mg} / \mathrm{l} \mathrm{BA}$ resulted in a medium response with the least response obtained with the medium- $\mathrm{D}$, in which, the presence of IAA also was not helpful. Therefore, the best response was obtained with medium-E with IAA, BA and Kn (Table 1) (Fig. 1A, B). This combination was formulated in order to replace the use of adenine sulphate in medium- $C$ which was expensive and also needed to be used in large quantities. Therefore the supplementation of IAA (1.0 
$\mathrm{mg} / \mathrm{l})+\mathrm{BA}(2.0 \mathrm{mg} / \mathrm{l})$ and $\mathrm{Kn}(2.0 \mathrm{mg} / \mathrm{l})$ in place of AS $(15.0 \mathrm{mg} / \mathrm{l})$ could elicit a higher if not a better response in both seedling and plantation trees explants.

Table 1. Response* of nodal explants from jojoba seedlings and trees cultured on different culture media (A to E).

\begin{tabular}{|c|c|c|c|c|c|}
\hline \multirow[t]{2}{*}{$\begin{array}{l}\text { Sl. } \\
\text { No. }\end{array}$} & \multirow[t]{2}{*}{$\begin{array}{l}\text { Culture } \\
\text { media }\end{array}$} & \multirow[t]{2}{*}{$\begin{array}{l}\text { No. of } \\
\text { explants } \\
\text { cultured }\end{array}$} & \multicolumn{2}{|c|}{$\begin{array}{l}\text { Percentage response of } \\
\text { production of multiple } \\
\text { shoots (Mean } \pm \text { S.E) }\end{array}$} & \multirow[t]{2}{*}{$\begin{array}{l}\text { No. of days } \\
\text { for the } \\
\text { response }\end{array}$} \\
\hline & & & $\begin{array}{l}\text { Seedling } \\
\text { explants }\end{array}$ & $\begin{array}{c}\text { Tree } \\
\text { explants }\end{array}$ & \\
\hline 1 & A: MS+ BA $(2.0 \mathrm{mg} / 1)$ & 100 & Nil & Nil & - \\
\hline 2 & B: MS+ BA (4. $0 \mathrm{mg} / \mathrm{l})$ & 100 & $80 \pm 4$ & $73 \pm 6$ & $21-35$ \\
\hline 3 & $\begin{array}{l}\mathrm{C}: \mathrm{MMS}+\mathrm{IAA}(1.0 \\
\mathrm{mg} / \mathrm{l})+\mathrm{BA}(0.5 \mathrm{mg} / \mathrm{l})+ \\
\text { ADS }(15.0 \mathrm{mg} / \mathrm{l})\end{array}$ & 100 & $86 \pm 6$ & $65 \pm 2$ & $21-30$ \\
\hline 4 & $\begin{array}{l}\mathrm{D}: \mathrm{MMS}+\mathrm{IAA}(1.0 \\
\mathrm{mg} / \mathrm{l})+\mathrm{BA}(4.0 \mathrm{mg} / \mathrm{l})\end{array}$ & 100 & $50 \pm 2$ & $48 \pm 3$ & $25-35$ \\
\hline 5 & $\begin{array}{l}\mathrm{E}: \mathrm{MMS}+\mathrm{IAA}(1.0 \\
\mathrm{mg} / \mathrm{l})+\mathrm{BA}(2.0 \mathrm{mg} / \mathrm{l})+ \\
\mathrm{Kn}(2.0 \mathrm{mg} / \mathrm{l})\end{array}$ & 100 & $95 \pm 1$ & $78 \pm 4$ & $21-30$ \\
\hline
\end{tabular}

*Percentage of total cultured nodal explants producing multiple shoots presented as mean \pm S.E. of the three replicates.

The shoot primordia which ultimately developed into clusters of multiple shoots by the third week were ready for rooting. To find the most suitable root inducing culture medium, in vitro elongated shoots $(2.5-3.0 \mathrm{~cm}$ long) regenerated from explants obtained from seedlings and plantation trees were transferred to different root induction media. Highest rooting response was recorded on MS + IBA (3.0 mg/l) $(90 \pm 7$ and $70 \pm 6$ in case of seedling and plantation tree explants. respectively). There was a moderate response on MS + IBA $(4.0 \mathrm{mg} / \mathrm{l})(30 \pm 2$ and $20 \pm 2$ in case of seedling and plantation tree explants, respectively) (Table 2). Initially, the development of the hairy roots (Fig. 1E) was observed after four to five weeks of transfer of shoots to the rooting medium followed by well-developed roots ( $2-3 \mathrm{~cm}$, long) after six to seven weeks (Fig. $1 F)$. Hence, the most efficient rooting medium standardized for jojoba was MS + IBA $(3.0 \mathrm{mg} / \mathrm{l})$. Rooted plantlets were transferred to pots in the laboratory (Fig. $1 \mathrm{G}$ ) and moved to glasshouse for acclimatization and later to field (Fig. 1H). Survival percentage values of plantlets transplanted to the Botanical Garden were $95 \pm 2$ and $92 \pm 1$ in case of plantlets regenerated from seedling and plantation tree explants, respectively (Table 2 ). 
Out of all the experiments conducted with various culture media, 126 and 75 plants from the seedling and plantation tree explants, respectively could be successfully established in the Botanical garden with a total of 201 plants in 8 months from the date of inoculation of explants. Further, the overall observations indicate that the micropropagation of seedling explants elicited a better response than that of plantation tree explants.
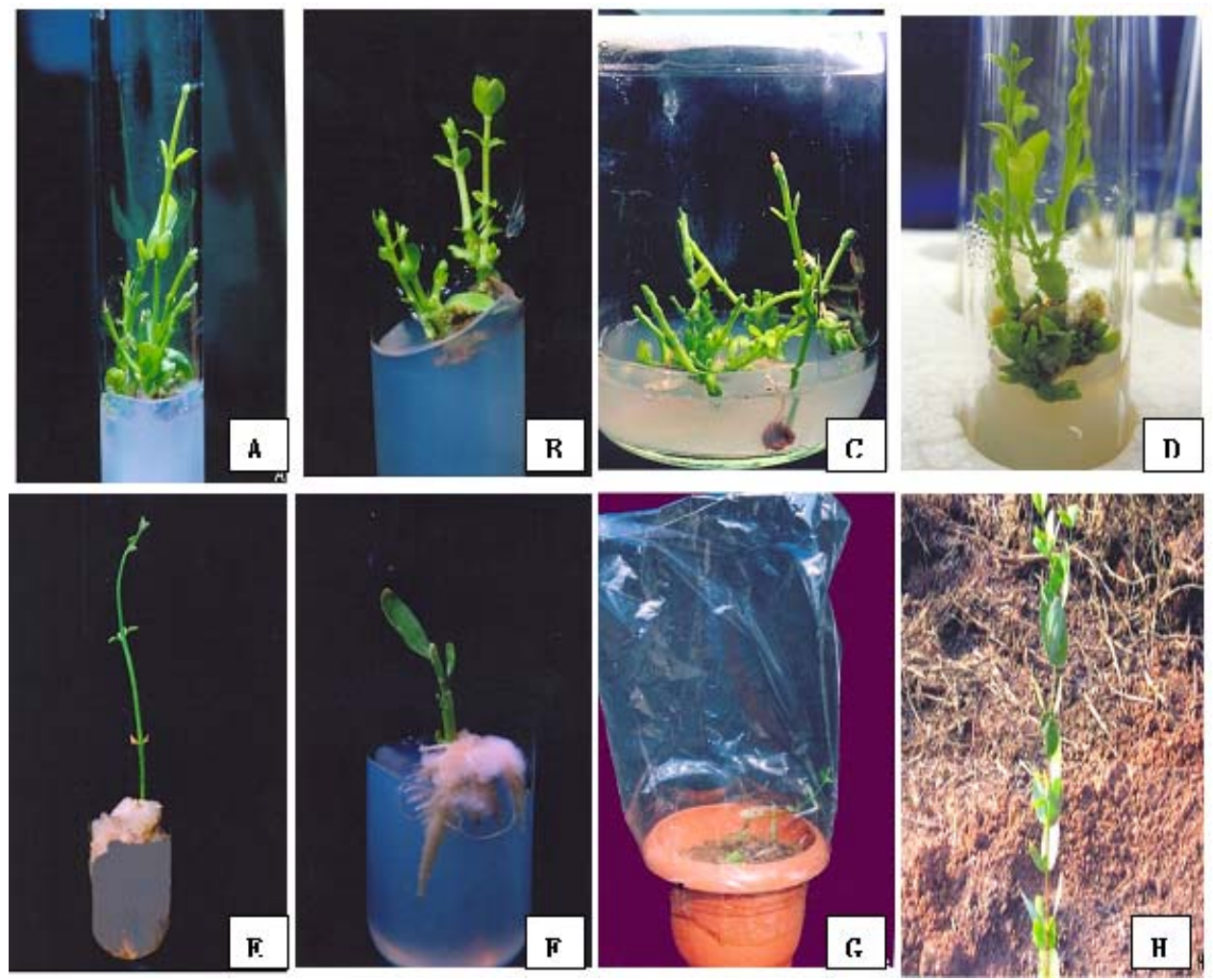

Fig. 1. Micropropagation of jojoba on different culture media. A. Regeneration of multiple shoots on culture medium-B from seedling explants. B. Regeneration of multiple shoots on culture medium-C from tree explants. C. Regeneration of multiple shoots on culture medium-D from seedling explants. D. Regeneration of multiple shoots on culture medium-E from tree explants. E. Rooting of regenerated shoots three weeks after transfer. F. Rooting of regenerated shoots six weeks after transfer. G. Acclimatization of rooted plant. H. Transfer of rooted plant to the field.

There are previous reports on multiple shoot regeneration of jojoba on various culture media viz. MS + Kn + BA (Kackar et al. 1993), MS + BA and MS + $\mathrm{IAA}+\mathrm{BA}+\mathrm{GA}_{3}$ (Llorente and Apostolo 1998), MS + BA (Khanam 1999 and Tyagi and Prakash 2004), $\mathrm{MS}+\mathrm{BA}$ and $\mathrm{MS}+\mathrm{BA}+\mathrm{AgNO}_{3}$ (Roussos et al. 1999); $\mathrm{MS}+$ BA and NAA (Meyghani et al. 2005). Although shoots were induced with the 


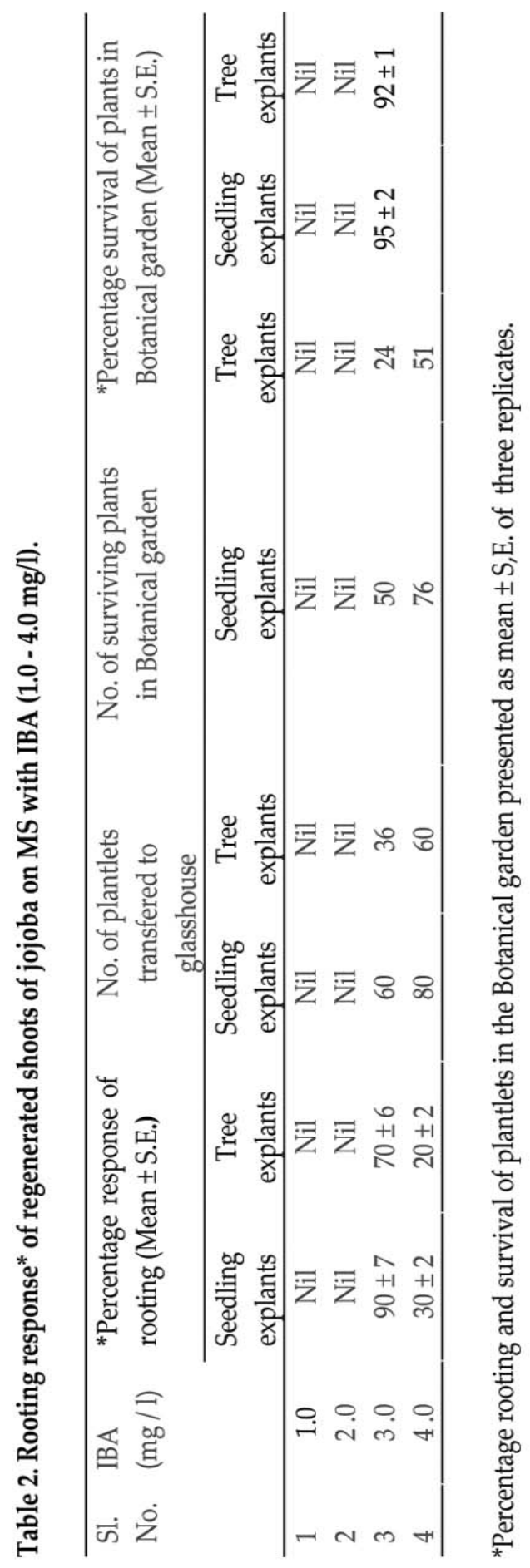


addition of BA to MS in the present study, a higher efficiency of multiple shoot induction was recorded on media-E and $C$ which were based on MMS. Of the two combinations, the medium-E with a combination of $\mathrm{Kn}$ elicited a higher response than that of medium-C with AS. Since AS is very expensive (Chaturvedi and Sharma (1989), the higher response achieved presently with relatively inexpensive $\mathrm{Kn}$ is a desirable improvement for high frequency micropropagation.

The rooting efficiency obtained presently was 90 and $70 \%$ in shoots regenerated from seedling and plantation tree explants, respectively. Similar results were recorded by Llorente and Apostolo (1998) and also during vegetative propagation (Low and Hackett 1981). Rooting was also reported earlier (Palzkil and Fieldman 1993, Roussos et al. 1999, Meyghani et al. 2005) when the rooting medium was supplemented with IBA and NAA or with IBA + IAA or caffeic acid (Chaturvedi and Sharma 1989) in contrast to the present results with only IBA.

The study therefore reports an efficient micropropagation protocol and highlights the importance of the seed-oil of jojoba in cosmetic industry.

\section{Acknowledgements}

The financial assistance received by first author (VR) from UGC-SERO under FDP program is gratefully acknowledged.

\section{References}

Chaturvedi HC and Sharma M (1989) In vitro production of cloned plants of jojoba (Simmondsia chinensis (Link) Schn.) through shoot proliferation in long-term culture. Pl. Sci. Lim. 63(2): 199-207.

Clifford LB and Wesley PH (1981) Vegetative propagation of jojoba. California Agriculture pp.12-13

Kackar NL, Joshi SP, Singh M and Solanki KR(1993) In vitro regeneration of female plants of Simmondsia chinensis (Link) Schneider using coppice shoots. Annals of Arid Zone. 32(3): 175-177.

Khanam A, Rao YBN and Farook SA (1999) Standard in vitro experimental protocol for high frequency mass micropropagation of jojoba (Simmondsia chinensis (Link) Schneider). Adv. Plant Sci. 12(2): 361-366.

Llorente BE and Apostolo NM (1998) Effect of different growth regulators and genotype on in vitro propagation of jojoba. New Zealand J. Crop Horti. Sci. 26(1): 55-62.

Meyghani H, Ghazvini RF and Hamidoghli Y (2005) Micropropagation from stem segments of salt tolerant jojoba seedlings. J. Korean Soc. Hortic. Sci. 46(3): 183-187. 
Palzkill DA and Feldman WR (1993) Optimizing rooting of jojoba stem cuttings: effects of basal wounding, rooting medium and depth of insertion in medium. JAOCS 70(12): 1221-1224.

Roussos PA, Marioli, AT, Pontikis CA and Kotsias D (1999). Rapid multiplication of Jojoba seedlings by in vitro culture. Plant Cell Tissue and Organ Culture 57(2): 133137.

Tyagi RK and Prakash S (2004) Genotype- and sex-specific protocols for in vitro micropropagation and medium-term conservation of jojoba. Biologia-Plantarum. 48(1): 19-23. 